\title{
National Coordination of Data and Information to Inform Land Use Policies and Programs: The Recent Past, the Present and Ideas for the Future
}

\author{
Richard Thackway
}

\section{Key Points}

- The Australian Government has responsibility for the development of national coordination arrangements for land use-related natural resource management (NRM) data and information to inform national land use policies and programs.

- If Australia wants a nationally coordinated approach to land use and land management, the Australian Government must provide consistent leadership and support - it is a matter of political and national will and mandate.

- So-called fundamental or core land use-related NRM national datasets are not immutable; as government NRM and land use policies change, so does the need for new or different fundamental datasets. 
- Effort should be invested in defining, collecting and improving data repositories that are based on essential environmental measures rather than derived environmental datasets. The later can be generated as required from the former.

- Enduring and widely used national NRM datasets, i.e. those that have been adopted and maintained for longer than 10 years, share similar characteristics (Box 9.1).

- National decision-makers require access to a wide variety of NRM data and information to improve land use policies and planningfor example, environmental flows. The greater the area being targeted, assessed or monitored, the greater is the need for national coordination and governance arrangements-for example, the Murray-Darling Basin Authority.

\section{Introduction}

The Australian Government has responsibility for the development of national coordination arrangements for land use related natural resource management (NRM) data and information to inform land use policy. This chapter is written from the perspective of a research scientist who was embedded in numerous science policy units in the Australian Government from 1984 to 2011 . Over that period, I was responsible for developing some key NRM data and information products that were subsequently used to inform science policy and influence NRM programs, and were widely recognised for their contribution to informing publicprivate decision-making. These products include bioregions (Thackway $\&$ Cresswell, 1995), Indigenous protected areas (Thackway, Szabo \& Smyth, 1997), weeds of national significance (McNaught, Thackway, Brown \& Parson, 2008), revegetation (Atyeo \& Thackway, 2009), native vegetation condition (Thackway \& Lesslie, 2008) and dynamic land cover (Thackway, Lymburner \& Guerschman, 2013). This role had its challenges, such as:

- producing timely, scientifically credible and policy-relevant advice and information, while keeping abreast of rapidly changing technological and scientific developments

- developing agreed and enduring natural resource data and information products that (to the extent possible) were neither partisan to those working in biodiversity conservation and protection, nor to those involved in sustainable land use and management 
- engaging with, and transcending, various public service cultures, including those who regarded the states and territories as a hindrance to developing consistent national data and information; those who believed that cutting budgets would not compromise development of the same or better-quality data and information products; and those who opposed scientists publishing their science policy-relevant work in the scientific literature, thereby restricting the development of their professional profile and standing.

Against these challenges, the following observations reflect my deep understanding of the characteristics of coordinated national land userelated policy and planning, NRM data and information; how these products are developed and maintained through partnerships; and how they are used in land use policy and planning and public programs at local, regional, state and national levels.

There has been an evolution in the operation of Australian government agencies and their relationships with data suppliers, particularly the states and territories, since the early 1980s. Five broad phases of national coordination can be recognised:

- Phase 1-before 1980: there was limited cross-border coordination between the states and territories. States and territories operated independently and were responsible for land use and management and developing natural resource data and information coordination and assessment programs.

- Phase 2-1980-99: the states and territories had significant natural resource data and information coordination and assessment programs and the Australian Government's national coordination was in its formative stage. National coordination had to be extensively promoted (e.g. Working Group for Land Resource Assessment).

- Phase 3-2000-07: the Australian Government sponsored and supported partnerships and bilateral agreements with the states and territories through national natural resource data and information coordination committees (e.g. those reporting to the Advisory Committee of the National Land and Water Resources Audit [NLWRA], the National Committee on Soil and Terrain, the Executive Steering Committee for Australian Land Use Mapping and the Executive Steering Committee for Australian Vegetation Information). 
These committees produced nationally agreed protocols and major national assessments that contributed to informing discussions on land use related policies.

- Phase 4-2008-13: the Australian Government dramatically reduced its role in sponsoring most national natural resource coordination organisations and committees; this included major reductions in funding to support collaboration with state land management agencies. Instead, it invested in the development of national natural resource data infrastructures (i.e. Australia-wide datasets) by directly funding research agencies and universities (e.g. the National Collaborative Research Infrastructure Strategy, Atlas of Living Australia [NCRIS ALA] and Terrestrial Ecosystem Research Network [TERN]). The states reviewed and revised their investments in national natural resource data and coordination with the Australian Government.

- Phase 5-2014 to present: the Australian Government has experienced significant declines in revenue. As a consequence, land use-related federal agencies have redefined their roles and responsibilities, including curtailing or terminating national coordination activities.

Numerous factors have contributed to this evolution, including:

- states and territories have not invested in the collection of new natural resource management (NRM) data and information since Phase 2

- significant advances in the speed of computing and the decreasing costs of computers and computer storage

- development of data infrastructure facilities that support major archives of spatial and temporal data and information (e.g. TERN)

- development of citizen science and online facilities to support standardised collection of field data and rapid connections between individuals and data warehouses (e.g. NCRIS ALA)

- development of more sophisticated modelling and scenario tools that are designed to ingest and analyse large multi-temporal image data archives (e.g. TERN facilities)

- growth of handheld personal communication tools and social media that enable individuals to collect, store, access, upload and download data and information from national data repositories

- growth in the legislative and regulatory powers of Australian government agencies and associated budgets that support data acquisition, data warehousing, analytics and internet access and reporting 
- growth in metadata systems, including the Australian Spatial Data Directory, which provide a national metadata hub for searching other national, state and territory directories to facilitate the discovery of published geospatial datasets throughout Australia.

Over recent years, the Australian Government's capacity to engage in coordination of land use-related policy and planning has been significantly reduced. One likely outcome of reduced budgets and functions is that the Australian Government may revise its former status as national coordinator for land use policy and planning (as described in Phases 1-2), which, given that the Australian Constitution vests responsibility for land use and management with the states and territories, would be justified.

If Australia wants a nationally coordinated approach, the Australian Government must provide leadership and support: it is a matter of political and national will and mandate. The Constitution aside, the Australian Government has responsibility for cross-jurisdictional issues of national and international significance. Moreover, it has signed various international treaties and conventions that carry responsibilities for monitoring and reporting. However, it must choose to exercise these responsibilities. Bilateral agreements have proven useful in the past; however, simply telling the states and territories that they are individually responsible for land management and NRM does not, itself, provide a nationally coordinated response.

\section{Data Needs Identification}

The Australian Government supports the acquisition of a wide array of biophysical, socio-economic and NRM-related data, and coordinates the development of information products for numerous land use and planning purposes. Most of these products require access to up-to-date, spatially accurate and policy-relevant data so that the information can be appropriately used to support policy development and improve decisionmaking.

Figure 9.1 shows a generic conceptual model that provides a convenient adaptive management framework for guiding the fundamental data and information items that are required-when, where and at what level of spatial and temporal detail (Thackway et al., 2013). This model, which has five key decision stages, has been used extensively in a science policy 
context (e.g. Thackway et al., 2013). For the purposes of illustration, the focus is on how the model can be used to determine the ecosystem services that are required by Australian and state government agencies, regional bodies and land managers.

This 'stepped cycle' model provides a framework that can be used for clarifying and addressing issues related to the what, why, how, when and where of future national resource management programs-specifically, how they can deliver better land use policy and program outcomes. The framework demonstrates how issues of scale of data can best be understood, and how this information can be used at each step of a strategic decision-making approach at different levels (national, regional and local). The key decision points provide useful checkpoints for reviewing and evaluating the appropriateness and relevance of data and information before proceeding to the next point. The model highlights both the gaps and need to collect new data before progressing to the next point. It is based on the premise that decisions should be supported by a clear appreciation of the data, information needs and priorities, sound understanding of the availability of suitable resources and options for their use, and capacity to measure, monitor and report changes in on-ground attitudes and support for land use and land management practices.

This model can be repeated in progress towards long-term objectives or, as necessary, in response to changing environmental conditions or policy and program priorities, and can be applied to different stakeholder groups operating at different spatial and temporal scales, such as public policy and program managers (e.g. federal and state governments), regional bodies (e.g. catchment management authorities) and land managers. There are interactions and crossovers between the different stakeholder groups. Collectively, these decision-makers may cooperate to deliver improved land use outcomes through adaptive management. Figure 9.1 illustrates these interactions with varying spatial and temporal scales, and is accompanied by a corresponding set of five broad decision points. 
1
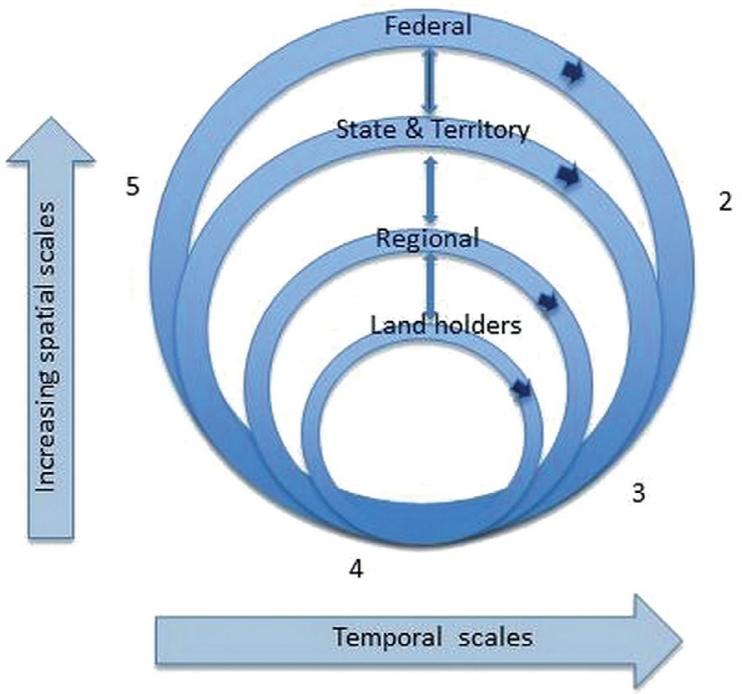

\section{Steps or decision points for managing land use-related NRM outcomes}

Step 1 Asset definition:

- Determine the appropriate landscape scale, characterise the mosaic of land use types and their ecosystem function (when and where).

Step 2 Identify land use characteristics:

- Determine the extent that the required ecosystem services are supplied by the current land use types and their ecosystem function and assess how the socioecological setting supports or limits their capacity.

Step 3 Identify needs for change:

- Determine if (and where in the landscape) changes in land management practices will maintain or enhance the condition of assets and hence improve the mix of ecosystem services.

Step 4 Identify and select options and implement priority actions:

- Set priorities for actions, consider trade-offs involved and identify areas for intervention whereby actions are to be undertaken through existing, revised or new policy and programs or changes in land management practices; invest in interventions that match selection criteria and monitor land use and land cover responses and links to ecosystem services and the effects of investments; and integrate relevant monitoring data with existing database systems.

Step 5 Evaluate the responses of the land cover to changes in land management practices:

- Analyse the spatial and temporal patterns and analyse how well the land use outcome met the desired goals and targets; repeat Steps $1-5$ as required.

Figure 9.1: Steps in assessing data and information required for science-policy applications.

Source: Thackway, Lymburner \& Guerschman (2013, modified from Figure 2). 
Figure 9.1 also shows the conceptual process for developing datasets that involve consideration of multiple spatial and temporal scales and various stakeholders; however, in practice, the situation is rarely this straightforward. Experience in developing regional-scale nationally consistent datasets that have been used by policymakers and planners for more than 10 years involves a complex interplay of applied science and research, federal-state and public-private relationship building, publication and marketing, enhancements and continuous improvement. Box 9.1 sets out the characteristics of enduring datasets that are based on sound national cooperation and collaboration, usually in partnership with the states and territories.

\section{Box 9.1: Characteristics of enduring datasets ${ }^{1}$ that are based on sound national cooperation and collaboration.}

1. Address a well-defined problem, issue or key questions

2. present an agreed conceptual model, framework or information hierarchy

3. have an effective champion, sponsor or leader

4. are underpinned by unambiguous governance arrangements

5. have a strong relevance to one or more policies and programs

6. are developed and maintained by recurrent adequate resourcing (people and $\sim \$$ )

7. are underpinned by sound technical, scientific and information technology (IT) support

8. are underpinned by sound data management enabling interoperability and a capacity to integrate

9. have sound data models enabling flexible information products to be generated

10. have been published and peer reviewed

11. are supported by custodians committed to continuous improvement (spatial and temporal)

12. are supported by a continuum of levels of detail, processing and standards

13. are discoverable, reusable and accessible

14. are relevant to research and education

15. are relevant to planners and on-ground managers

16. are relevant to key clients or partners

17. represent the ideal 'the whole is more than the sum of its parts' (i.e. products add value to the inputs from jurisdictions).

1 Regional-scale national datasets that are used by policy and planning for more than 10 years. 


\section{Influence Monitoring through Developing and Promoting Core National Attributes}

Beyond its importance for design and implementation of policies and programs, national coordination of key land use-related NRM data and information has been vital to the monitoring, evaluation, reporting and improvement of policies and programs. While millions of dollars have been invested in public land use-related NRM policies and programs, a review of the Natural Heritage Program in 2008 was unable to assess whether existing management interventions had solved the environmental problems related to adverse effects of land use and land management, or whether the investment had been cost-effective (Australian National Audit Office, 2008). The critical issue was gaining access to the up-todate, detailed spatial and temporal information necessary to ascertain how successful the interventions were, given their apparent need.

Evidence-based land use-related NRM policy and program settings that are founded on credible spatial and temporal data and information can make a stronger case for early interventions, renewed funding and sound evaluations of performance. The development of nationally consistent regional-scale mapped datasets is commonly based on the relevant Australian government agency working with appropriate state and territory land management agencies to develop protocols and supporting datasets. The process is characterised by the Australian Government initiating, sponsoring and sometimes funding cooperative and collaborative projects under an appropriate executive science policy governance arrangement. The period between 2000 and 2005 saw the rapid development of online data collection and mapping tools that, combined with high-speed data transfer developments, were quickly accepted and promoted by land use policy and program managers as platforms for improving the efficiency and effectiveness of program delivery and performance monitoring.

The control and management of weeds of national significance (WONS) and the need to use revegetation to address a wide range of NRMrelated issues arising from over-cleared landscapes are two cases of national coordination of core attribute data. Core attributes represent the minimum number of features that are required in surveying, mapping, monitoring and reporting across different scales. The obvious advantage of using standardised national core attributes is that new data collected 
using these protocols are more likely to be spatially consistent across scales and over time, and existing data can be transposed where they fit the attribute minimum standards.

Core attributes have been developed for WONS by McNaught et al. (2008) and for revegetation by Atyeo and Thackway (2009) through extensive consultation with national, state and regional program managers and on-ground local-scale project practitioners. High-level councils contributed to the recognition of core attributes for use in state and national public programs; WONS involved the Australian Weeds Council and revegetation involved the NLWRA.

Core attributes have been used to improve design, delivery and performance of NRM programs at the strategic and tactical levels. At the strategic level (i.e. regional, state and national scales), attributes describing the type, extent and distribution of weeds and revegetation are required for a range of purposes. Monitoring at this scale is sometimes described as 'surveillance monitoring'. The WONS surveillance maps were used to design and implement the Australian Government's Defeating the Weed Menace program by targeting areas for control of new weed incursions. Surveillance maps of over-cleared landscapes were used to target revegetation programs, including Landcare, Bushcare, Rivercare, the Natural Heritage Trust, Corridors of Green, Greening Australia, Envirofund and Caring for our Country. At the tactical level, core attributes have also been influential in designing on-ground projects and documenting the outcomes of management activities. Monitoring at this scale is described as 'investigative monitoring'.

\section{Informing Land Use Debates Using High-Quality Fundamental Datasets}

Scientifically based information, or fundamental data, that everyone can agree on and trust should underpin land use and land management debates. Information about land use is especially important for better management of natural resources. The role of a data provider delivering these fundamental datasets is a critical component of the debate. The provider must be trusted and the information must have a welldocumented pedigree to ensure its integrity (i.e. metadata). The general community, industry and developers share an interest in and require access to information sets. The Australian Government has been a provider of 
such land use datasets information under the auspices of the Australian Collaborative Land Use and Management Program (ACLUMP, 2010). Membership of ACLUMP includes Australian, state and territory government partners. The Australian Land Use and Management Classification has been adopted by all partner agencies and is supported by nationally agreed technical standards.

Commencing in 2008, ACLUMP made Australia-wide land use mapping available at national and regional (catchment) scales. National-scale maps $(1: 2,500,000)$ and data are available online for a series of years from 1992-93 to 2005-06. Catchment and regional maps are available at a variety of scales-1:25,000 to 1:100,000 — except in sparsely settled areas, where the recommended scale is $1: 250,000$. The currency of catchment-scale mapping ranges from 1997 to 2015 .

Land use data provide context that is important, and often essential, to meeting the information needs for monitoring, evaluation and reporting against indicators used by natural resource management programs. Land use-related NRM datasets are variously used for policy initiatives, including establishing opportunities and barriers for resource development, populating particular indicator frameworks (State of the Environment [SoE], 2011), contributing to long-term records (e.g. bushfire and climate databases) or developing scenarios of the projected extent and condition of natural resources and environmental variables under different land use futures. Similarly, baseline spatial and temporal information on land management practices is essential for monitoring and reporting on progress towards long-term resource condition outcomes.

On a global scale, land use-related issues have been shown to have significant effects on protective functions and ecosystem services of global forests (Miura et al., 2015). At this scale, land use and how the land is managed have obvious effects on the condition of native vegetation and consequences for biodiversity (Thackway, 2016). On a national scale, evidence has shown that, by combining land use data and information with other NRM datasets (e.g. land salinity) and native vegetation (NLWRA, 2007, 2008a, 2008b), key questions can more readily be answered, such as:

- What is the nature and extent of the issue and how does it relate to land use?

- Is the existing or proposed land management intervention appropriate for the size of the issue? 
- What types of land management intervention work best, are most cost-effective and have the best transferability across regions?

- What was the impact of the land use-related policy or program investment-in the intermediate and long term?

Monitoring and evaluation of core indicators support evidence-based decision-making at national, state, territory, regional and land manager levels (see Figure 9.1). Three national examples in which land use-related NRM data and information are critical for regular national monitoring and reporting are the national SoE (2011), state of the forest reports (Montreal Process Implementation Group for Australia and National Forest Inventory Steering Committee, 2013) and regional environmental accounting (Sbrocchi et al., 2015). Figure 9.1 acknowledges that decisionmakers may have a wide variety of data and information needs in terms of content, context or spatial and temporal scales at each level. Equally, there is complexity across these four levels due to multiple needs, values, preferences and time frames.

As noted above, we have seen the waxing and waning of national coordination since the late 1970s. The demise of key coordination agencies, such as Land and Water Australia and NLWRA and the diminution of support for most national coordinating committees have created a vacuum in national coordination of data and information to inform land use policies and programs. Given the critical nature of land use and land management data to land use decision-making, clearly much more needs to be done. National coordination is needed in the following key areas:

- identifying fundamental datasets to support key agency policies and programs, such as Australian Bureau of Agricultural and Resource Economics and Sciences (Mutendeudzi \& Stafford-Bell, 2011)

- identifying key collection agencies and funding them to collect fundamental data, as proposed in the National Plan for Environmental Information (Australian Government Environmental Information Advisory Group, 2012)

- clarifying the future role of citizen science in collecting land use and management data

- supporting the development of, and investing in, essential environmental measures that underpin national datasets, which are critical for land use decision-making, including monitoring and reporting, program design and evaluation 
- clarifying whether we should legislate data collection and transfer (e.g. the National Water Act 2007)

- clarifying what agency at the federal level has carriage for undertaking sustainability assessments (e.g. the Productivity Commission).

\section{Acknowledgements}

Chris Auricht, Shane Cridland, Peter Wilson, Blair Wood and Graham Yapp provided comments on an earlier draft.

\section{References}

ACLUMP (Australian Collaborative Land Use and Management Program). (2010). Land use and land management information for Australia: Workplan of the Australian Collaborative Land Use and Management Program. Canberra, ACT: Australian Bureau of Agricultural and Resource Economics and Sciences.

Atyeo, C. \& Thackway, R. (2009). Mapping and monitoring revegetation activities in Australia-towards national core attributes. Australasian Journal of Environmental Management 16(3), 140-48. Retrieved from search.informit.com.au/document Summary;dn=071365261532926; res=IELBUS

Australian Government Environmental Information Advisory Group. (2012). Statement of Australian Government requirements for environmental information. Canberra, ACT: Bureau of Meteorology.

Australian National Audit Office. (2008). Regional delivery model for the natural heritage trust and the national action plan for salinity and water quality. Canberra, ACT: Departments of the Environment, Water, Heritage and the Arts and Agriculture, Fisheries and Forestry. Retrieved from www.anao.gov.au/uploads/documents/2007-08_Audit _Report_21.pdf

McNaught, I., Thackway, R., Brown, L. \& Parsons, M. (2008). A field manual for surveying and mapping nationally significant weeds (2nd ed.). Canberra, ACT: Bureau of Rural Sciences. 
Miura, S., Amacher, M., Hofer, T., San-Miguel-Ayanz, J., Ernawati \& Thackway, R. (2015). Protective functions and ecosystem services of global forests in the past quarter-century. Forest Ecology and Management 352, 35-46. doi.org/10.1016/j.foreco.2015.03.039

Montreal Process Implementation Group for Australia and National Forest Inventory Steering Committee. (2013). State of the forests report. Canberra, ACT: Australian Bureau of Agricultural and Resource Economics and Sciences.

Mutendeudzi, M. \& Stafford-Bell, R. (2011). Scientific information for making decisions about natural resource management - a report on the value, status and availability of key ABARES datasets (ABARES Technical Report 11.2). Canberra, ACT: Australian Bureau of Agricultural and Resource Economics and Sciences.

NLWRA (National Land and Water Resources Audit). (2007). Native vegetation - status of information for reporting against indicators under the national natural resource management monitoring and evaluation framework. Canberra, ACT: National Land and Water Resources Audit.

NLWRA. (2008a). Land use-status of information for reporting against indicators under the national natural resource management monitoring and evaluation framework. Canberra, ACT: National Land and Water Resources Audit.

NLWRA. (2008b). Land salinity—status of information for reporting against indicators under the national natural resource management monitoring and evaluation framework. Canberra, ACT: National Land and Water Resources Audit.

Sbrocchi C., Davis R., Grundy M., Harding R., Hillman T., Mount R., ... Cosier, P. (2015). Evaluation of the Australian regional environmental accounts trial. Sydney, NSW: Wentworth Group of Concerned Scientists.

SoE (State of the Environment Committee). (2011). Australia state of the environment. Independent report to the Australian Government Minister for Sustainability, Environment, Water, Population and Communities. Canberra, ACT. Retrieved from www.environment.gov.au/science/soe/2011-report/5-land/2-stateand-trends/2-3-vegetation\#ss2-3-1 
Thackway, R. (2016). Tracking anthropogenic influences on the condition of plant communities at sites and landscape scales. In A. Z. K. Almusaed (Ed.), Landscape ecology — the influences of land use and anthropogenic impacts of landscape creation. London, UK: InTech. doi.org/10.5772/62874

Thackway, R. \& Cresswell, I. D. (Eds.). (1995). An interim biogeographic regionalisation for Australia: A framework for establishing the national system of reserves (version 4.0). Canberra, ACT: Australian Nature Conservation Agency.

Thackway, R. \& Lesslie, R. (2008). Describing and mapping humaninduced vegetation change in the Australian landscape. Environmental Management 42, 572-90. doi.org/10.1007/s00267-008-9131-5

Thackway, R., Lymburner, L. \& Guerschman, J. P. (2013). Dynamic land cover information: Bridging the gap between remote sensing and natural resource management. Ecology and Society 18(1), 2. doi.org/ 10.5751/ES-05229-180102

Thackway, R., Szabo, S. \& Smyth, D. (1997). Indigenous protected areas: New opportunities for the conservation of biodiversity. In P. Hale \& D. Lamb (Eds.), Proceedings of the conference on conservation outside of nature reserves (pp. 62-73). Brisbane, QLD: Centre for Conservation Biology, University of Queensland. 
This text is taken from Land Use in Australia: Past, Present and Future, edited by Richard Thackway, published 2018 by ANU eView, The Australian National University, Canberra, Australia.

doi.org/10.22459/LUA.02.2018.09 